\title{
Effects of electrically-stimulated exercise and passive motion on echocardiographically-derived wall motion and cardiodynamic function in tetraplegic persons
}

\author{
MS Nash ${ }^{1,4}$, MS Bilsker ${ }^{2,5}$, HM Kearney ${ }^{4}$, JN Ramirez ${ }^{5}$, B Applegate ${ }^{1}$ and BA Green ${ }^{3,4}$ \\ Departments of ${ }^{1}$ Orthopaedics and Rehabilitation, ${ }^{2}$ Medicine, ${ }^{3}$ Neurological Surgery, and the ${ }^{4}$ Miami Project, \\ University of Miami School of Medicine; ${ }^{5}$ Echocardiography Laboratory, Jackson Memorial Hospital, Miami, \\ FL 33101, USA
}

The purposes of the study were (1) to characterize left ventricular wall motion, and the cardiodynamic and metabolic responses during electrical stimulation cycle ergometry (ESCE) exercise in tetraplegic people; (2) to test whether these responses linger into the post-exercise recovery period; and (3) to test whether they differ from those imposed by lower extremity continuous passive motion (CPM). Subjects were six tetraplegic males aged $25.8 \pm 3.1$ (mean $\pm \mathrm{SD}$ ) years with spinal cord injuries of $6.7 \pm 3.5$ years' duration at the C5 and C6 levels (Frankel classifications A and B). On randomized non-consecutive days, subjects underwent either $30 \mathrm{~min}$ of steady-state exercise using transcutaneous electricallystimulated contractions of bilateral quadriceps, hamstring, and gluteus muscle groups, or $30 \mathrm{~min}$ of continuous passive motion at $50 \mathrm{rpm}$. Data were taken at rest, min 15 and 30 of treatment, and $\min 5,15$, and 30 post-treatment. Stroke volume (SV) was measured echocardiographically as the product of the left ventricular outflow tract area and the integrated area under the left ventricular outflow tract flow-velocity curve acquired by doppler ultrasound. This value was multiplied by heart rate (HR) to determine the cardiac output $(\mathrm{CO})$. Oxygen consumption $\left(\mathrm{VO}_{2}\right)$ was monitored spirometrically, with arteriovenous oxygen difference $\left(\mathrm{a}-\mathrm{vO}_{2 \mathrm{DIFF}}\right)$ computed algebraically. Data were analyzed using repeated measures within-subjects design anaysis of variance, with significance accepted at the 0.05 level. Results showed five subjects had small hyperkinetic ventricles at rest that became more dynamic during ESCE than CPM. Though no systolic dysfunction was noted, all but one subject exhibited some degree of septal hypokinesis at rest and during exercise, possibly indicative of left ventricular noncompliance. Significant effects of condition (ESCE vs CPM), trial (measurement time point), and their interaction, were observed for $\mathrm{CO}$ $(P<0.05,0.01$, and 0.0001 , respectively), HR $(P<0.0001,0.05$ and 0.005 , respectively), and $\mathrm{VO}_{2}(P<0.001,0.05$ and 0.005 , respectively). A significant trial and condition by trial interaction was found for a-vO 2 DIFF $(P<0.05$ and 0.0001 , respectively). No effects for condition, trial or their interaction were found for $\mathrm{SV}$ or $\mathrm{BP}_{\mathrm{DIAS}}$. Electrical stimulation cycle ergometry-treated subjects achieved peak $\mathrm{VO}_{2}$ of $712 \pm 300 \mathrm{ml} \mathrm{min}^{-1}, 2.63$ times baseline, with $56 \%$ elevation of a-vO $\mathrm{vDIFF}_{\text {D }}$. Cardiac output increased from $3.5 \pm 1.51 \mathrm{~min}^{-1}$ to $6.0 \pm 2.11 \mathrm{~min}^{-1}$, an elevation solely attributable to a $57 \%$ increase in $\mathrm{HR}$. Thus, both $\mathrm{CO}$ and a-vO $\mathrm{V}_{2 \mathrm{IFF}}$ accounted for elevated $\mathrm{VO}_{2}$ during ESCE. These results show (1) that cardiac hyperkinesis with small ventricles and reduced septal motion occurs at rest and during ESCE in tetraplegics; (2) that ESCE, but not CPM, modifies cardiac and metabolic functions from baseline; (3) that CO elevation during ESCE is solely attributable to HR increase; and (4) that cardiac and metabolic functions, excluding HR, return to baseline rapidly following completion of ESCE.

Keywords: tetraplegia; exercise, cardiac atrophy; echocardiography; electrical stimulation

Correspondence: Mark S Nash PhD, Division of Physical Therapy, Department of Orthopaedics and Rehabilitation, University of Miami School of Medicine, 5915 Ponce de Leon Blvd, 5th Floor, Coral Gables, Florida 33146 USA

\section{Introduction}

Cardiovascular decompensation in persons surviving tetraplegia results in dramatically modified cardiac structure and function. These changes are character- 
ized, in part, by loss of left ventricular (LV) mass, diminished ventricular chamber size and wall thicknesses, rightward shift of the cardiac electrical axis, and abnormal motion of the cardiac posterior wall within the atrioventricular groove. ${ }^{1}$ Pathological alterations of cardiac structure and function in tetraplegics result from sustained underloading of the LV myocardium due to chronically depressed cardiac filling volumes and restricted contraction rates, consequences of vasomotor dysregulation and protracted physical immobilization normally accompanying the tetraplegic condition. ${ }^{2,3}$ As cardiopulmonary complications now represent the major cause of mortality in survivors of tetraplegia, ${ }^{4}$ as well as a major source of morbidity in those who are aging with spinal cord injury (SCI), ${ }^{5}$ cardiac atrophy associated with longstanding ventricular underloading may hasten the decline of cardiac pump function and thus, cardiac output over time. It may also contribute in part to the long-term cardiopulmonary morbidity profile in this population.

Cardiorespiratory endurance training and strength training performed by persons without disability have both been shown to augment myocardial mass, ${ }^{6,7}$ albeit by different mechanisms. Endurance exercise training increases cardiac mass by promoting larger LV internal dimensions without meaningful alteration of cardiac wall thickness. ${ }^{8}$ Conversely, strength training promotes an increased thickness of the interventricular septum and posterior wall without change in LV chamber size. ${ }^{9}$ More recently, cardiac atrophy in individuals with chronic tetraplegia was reversed following 6 months of cycling exercise using transcutaneous electricallystimulated contractions of lower extremity muscles. ${ }^{10}$ As the observed increases in cardiac mass were attributable both to increased LV chamber dimensions and non-pathological thickening of the interventricular septum and posterior walls, it was postulated that cardiac adaptation was stimulated through both volume and pressure overloading of the cardiovascular system relative to the resting state. This hypothesis was speculative however, as volume and pressure challenge to the heart as assessed by direct measurement of cardiac output $(\mathrm{CO})$, stroke volume (SV), heart rate (HR), mean arterial pressure (MAP), and cardiac wall motion were not measured in the study.

It has previously been shown that the oxygen uptake $\left(\mathrm{VO}_{2}\right)$, arteriovenous oxygen difference $\left(\mathrm{a}-\mathrm{vO}_{2 \mathrm{DIFF}}\right)$, $\mathrm{CO}, \mathrm{SV}$, and HR of tetraplegics are all significantly increased during periods of electrical stimulation cycle ergometry (ESCE) exercise. ${ }^{11-13}$ The observation that acute responses by tetraplegic patients to ESCE exercise ultimately result in sustained changes in cardiac architecture is important, as (1) metabolic changes from baseline during ESCE are modest when compared to those of persons without disability undergoing voluntary cycling exercise, ${ }^{11-13}$ and (2) autonomic dysfunction accompanying cervical SCI blunts the usual exercise-induced sympathetic nervous system response that stimulates positive cardiac chronotropy (ie rate) and inotropy (ie contractility), and increased systemic arterial pressure. ${ }^{14}$
To date, the questions as to whether (1) cardiac wall motion of individuals with tetraplegia is altered during either electrically-stimulated exercise or passive motion of the lower extremities, and (2) the walls of the heart contract synergistically during ESCE exercise, have yet to be addressed. Moreover, as elevated HR and myocardial force of contraction contribute to cardiac work performed long after cessation of physical activity in persons without disability, ${ }^{15}$ and as post-exercise oxygen consumption also remains above baseline after termination of physical activity, ${ }^{16}$ the cardiodynamic and metabolic states in the post-ESCE period have yet to be scrutinized. Thus, the purpose of this study was to characterize acute $\mathrm{LV}$ wall motion, and cardiodynamic and metabolic responses in tetraplegic people during and following acute ESCE exercise, and to test whether these responses differ from those imposed by continuous passive motion (CPM).

\section{Methods}

\section{Subjects}

Six tetraplegic males aged $25.8 \pm 6.7$ (mean \pm SD) years with SCI of $6.7 \pm 3.5$ years' duration at the C5 and C6 levels were studied. All subjects had either clinically complete upper motor neuron lesions without preserved motor or sensory function (Frankel classification $\mathrm{A}$ ), or absence of volitional motor function below the level of lesion, but some preserved sensation (Frankel classification B). None of the subjects had volitional bowel or bladder function and in all cases their physical disability was attributable to SCI alone. Participants were in good health defined operationally as asymptomatic for treatable illness. Blood chemistries performed before the initiation of treatment showed that all subjects had normal white and red blood cell counts, protein, and albumin. Twelve lead electrocardiograms showed no disturbances of rhythm, ischemia, or, evidence of prior myocardial infarction. Range of motion of the lower extremitites was within functional limits for each subject, and none had evidence of bone or joint pathology. Radiographic examination confirmed the absence of lower extremity fractures and implanted metal instruments. Parasternal and apical echocardiograms showed no cardiac structural anomalies or mitral valve prolapse. Subjects consented to participate in the study in accordance with guidelines of the institutional Medical Sciences Subcommittee for the Protection of Human Subjects. Descriptive characteristics of the subjects are shown in Table 1.

\section{Exercise training}

Subjects underwent 1 month of quadriceps muscle training using transcutaneous electrical current (compensated monophasic rectangular wave, $40 \mathrm{~Hz}, 375$ microseconds pulse duration, constant current, Therapeutic Technologies Inc, Tampa, Florida) introduced to the anterior thigh using three carbon silastic electrodes. Subjects were trained three times weekly on non-consecutive days using a progressive resistance 
Table 1 Descriptive characteristics of the study subjects

\begin{tabular}{|c|c|c|c|c|c|}
\hline Subject & $\begin{array}{l}\text { Level of } \\
\text { injury }\end{array}$ & Frankel class & $\begin{array}{l}\text { Age } \\
\text { (yrs) }\end{array}$ & $\begin{array}{c}\text { Duration of injury } \\
(y r s)\end{array}$ & Wheelchair propulsion \\
\hline 1 & C5, 6 & A & 23 & 3 & Power \\
\hline 2 & $\mathrm{C} 5$ & B & 30 & 13 & Manual/limited \\
\hline 3 & C5, 6 & B & 30 & 8 & Manual/independent \\
\hline 4 & C5 & A & 23 & 3 & Manual/dependent \\
\hline 5 & C5, 6 & B & 26 & 5 & Manual/independent \\
\hline 6 & C5 & A & 23 & 8 & Power \\
\hline Mean & & & 25.8 & 6.7 & \\
\hline SD & & & 3.1 & 3.5 & \\
\hline
\end{tabular}

exercise algorithm. During each training session the seated subjects performed 45 repetitions of electricallystimulated knee extension through $45^{\circ}$ range from the $90^{\circ}$ gravity-dependent position. All subjects began training with a one pound weight attached to their ankle. When the subjects were able to complete the targeted 45 repetitions, the weight was increased by two pounds for the next training session. If the subject was unable to complete this designated number of contractions, the weight was reduced by one pound. Each quadriceps contraction lasted 6 s (3 s concentric, $3 \mathrm{~s}$ eccentric) with a $14 \mathrm{~s}$ rest period between lifts.

Following the quadriceps muscle training phase, subjects underwent cycle ergometry training three times weekly on non-consecutive days. Subjects were prepared for electrically-stimulated cycling using three carbon silastic electrodes placed over the bilateral quadriceps, hamstring and gluteus muscle groups. Cycling was performed in the seated position using computer-sequenced electrical current (same stimulus parameters as before) for 30 min each training session. Subjects began training without external resistance applied to the ergometer. When they could tolerate $30 \mathrm{~min}$ continuous steady-state cycling without the onset of fatigue, the resistance was increased by $1 / 8$ kilopound. Fatigue was determined operationally by the inability of the subject to maintain a pedal rate greater than 35 revolutions per min (rpm) during peak current stimulation at 130 milliamperes. Subjects selected for study were those who could sustain 30 min uninterrupted cycling, and had been habituated to ESCE treatment for 4-8 months.

\section{Testing conditions}

On randomized non-consecutive days within a 1 week period subjects were tested under each of the following randomized conditions: (1) $30 \mathrm{~min}$ steady-state cycling using electrically-stimulated contractions of the bilateral quadriceps, hamstring, and gluteus muscle groups, or (2) $30 \mathrm{~min}$ cycling via continuous passive motion (CPM) at $50 \mathrm{rpm}$. To test responses to ESCE, subjects were prepared as described above, transferred to the seated position on the ergometer, and allowed $15 \mathrm{~min}$ to return to a fully resting state. Subjects then pedaled at the greatest resistance during which a rate greater than $35 \mathrm{rpm}$ could be maintained for 30 uninterrupted min. Movement of the arms and trunk were restricted so that work responses solely reflected electrically-stimulated lower extremity muscle contractions.

On days when the CPM condition was tested, the subject were managed identically, although a resistive ('dummy') load was applied across the electrode leads of the electrical stimulation device which caused it to display the CPM pedal rate of $50 \mathrm{rpm}$ while not providing stimulation for the subject.

Data were collected with subjects seated at rest on the cycle, min 15 and 30 of treatment, and min 5, 15 and 30 post treatment.

\section{Echocardiography}

Echocardiograms were recorded on a Hewlett Packard Sonos 1000 echocardiographic system (Andover, Massachusettes) while subjects were seated on the ergometer. The better of apical or parasternal views was used to visualize the left ventricular outflow tract (LVOT) (Figure 1) and digitize its diameter (Figure 2). The LVOT cross-sectional area was computed via software resident on the echocardiographic system. A doppler flow study was then performed through the

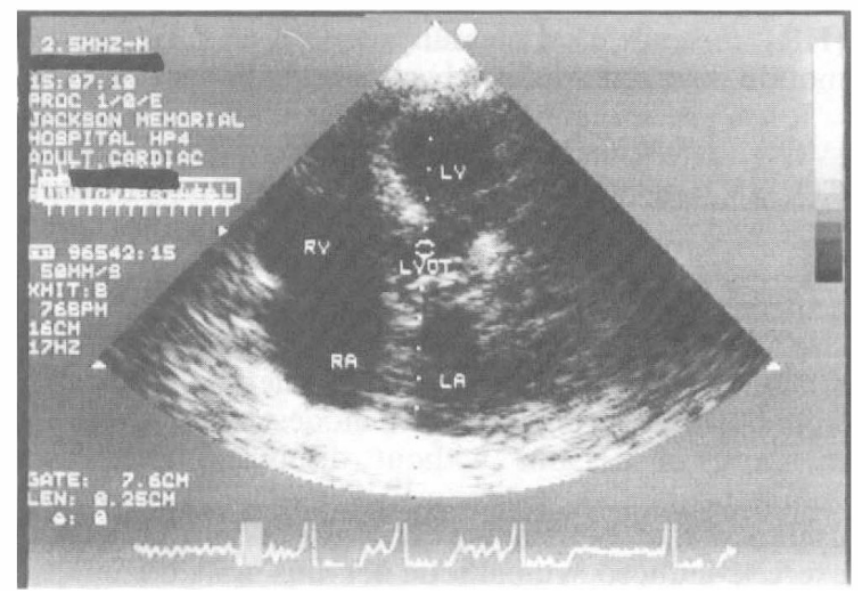

Figure 1 2-D apical four-chamber echocardiogram showing location of the LVOT relative to the right and left atria (RA and LA), and right and left ventricles (RV and LV) 


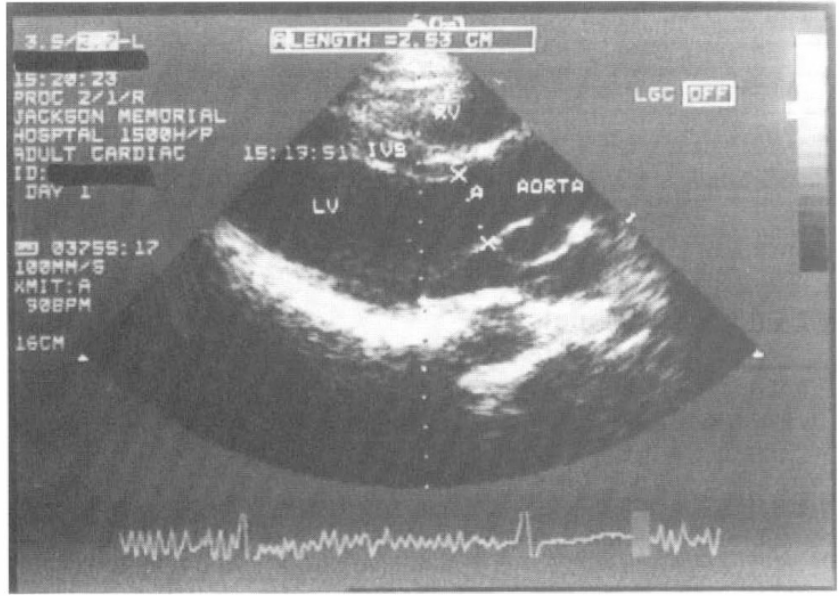

Figure 2 Parasternal long-axis view showing the LVOT in cross-section. The LVOT diameter is digitized between the two Xs. IVS is the interventricular septum

LVOT yielding the flow-velocity curve for this region (Figure 3 ). The area under two successive cardiac cycle curves was digitized to give the flow-velocity integral. Stroke volume was then computed algebraically using the LVOT area and the flow-velocity integral. Cardiac output was quantified by multiplying the SV by the $H R$, the latter derived from the $R-R$ interval of an echocardiograph-superimposed EKG tracing specific to the cardiac cycle curves being measured (Figure 3).

\section{Metabolic assessment}

Oxygen consumption was monitored via open-circuit spirometry on a Horizon System V metabolic measurements analyzer (Sensormedics Inc, Yorba Linda, California) using a Hans-Rudolph non-rebreathing mask. Arteriovenous oxygen difference was computed as the quotient of the $\mathrm{CO}$ derived echocardiographically and the $\mathrm{VO}_{2}$ measured spirometrically. Mean arterial press-

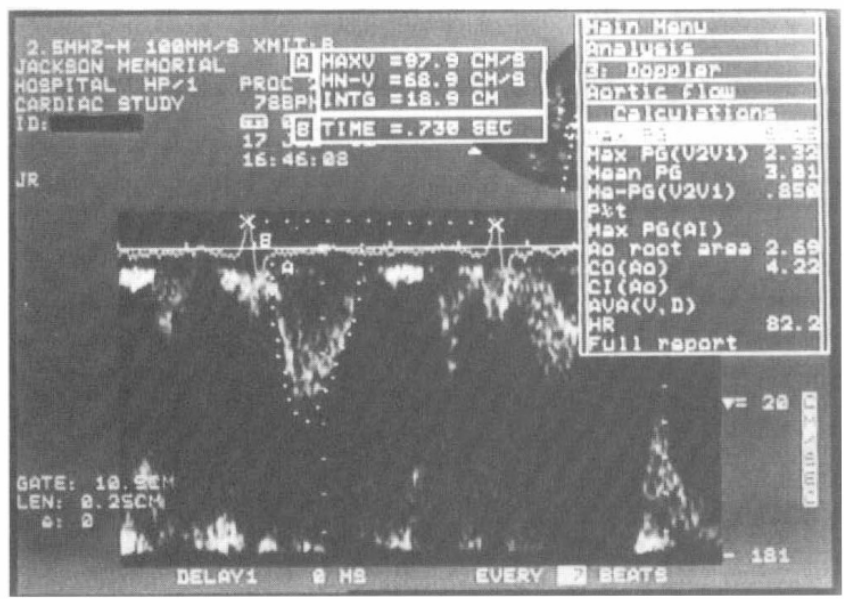

Figure 3 Measurement of SV by doppler ultrasound. The area under the digitized line is the flow-velocity integral which is then multiplied by the heart rate $(\mathrm{X} \ldots \mathrm{X})$ from the superimposed EKG to derive $\mathrm{CO}$ ure was set as the sum of the diastolic blood pressure $\left(\mathrm{BP}_{\text {DIAS }}\right)$ plus one third the pulse pressure $\left(\mathrm{BP}_{\text {DIAS- }}\right.$ - systolic blood pressure $\left(\mathrm{BP}_{\mathrm{SYS}}\right)$.

\section{Statistical analysis}

Data were analyzed using repeated measures design two-way within-subjects analysis of variance (ANOVA), with statistical significance accepted at the 0.05 level. Operationally, the main effect for 'condition' tested for differences between ESCE and CPM; the main effect for 'trial' tested for differences among measurement time points (baseline, $15 \mathrm{~min}$... 30 post); and the 'interaction' tested for differences among conditions over trials.

\section{Results}

Results showed that five of the six subjects had small hyperkinetic ventricles at rest and during ESCE without evidence of systolic dysfunction. This finding is attributable to chronically depressed cardiac filling volumes in tetraplegic persons in the resting state. Septal hypokinesis was also observed in the same five subjects both at rest and during ESCE (Figure 4). Normal motion was present at rest in the single subject with a largest LV. Significant effects for condition (ESCE vs CPM), trial (measurement time point), and their interaction, were observed for $\mathrm{CO}(P<0.05$, 0.01 , and 0.0001 , respectively $), \mathrm{HR}(P<0.0001,0.05$ and 0.005 , respectively), and $\mathrm{VO}_{2}(P<0.001,0.05$, and 0.005 , respectively) (Table 1$)$. A significant effect for trial and the condition by trial interaction was found for a-vO ${ }_{2 \text { IFF }}(P<0.05$ and 0.0001 , respectively $)$. Subsequent analysis of the interaction focused on identifying the simple main effects (ie the analysis of the interaction which examines for differences between ESCE and CPM e(condition) at each measurement time point). Analysis of the simple main effects for the dependent variable $\mathrm{CO}$ indicated that conditions were

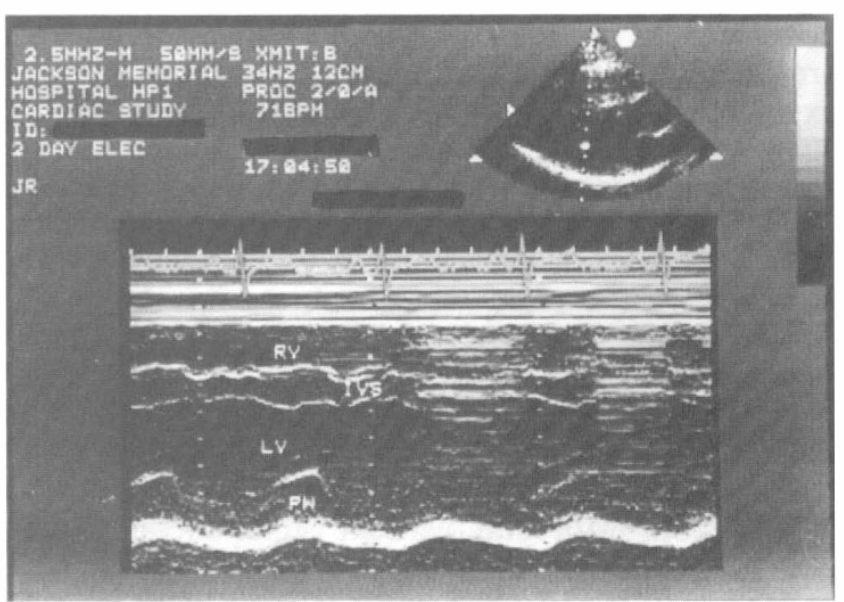

Figure 4 Baseline M-mode echocardiogram showing the right ventricle $(\mathrm{RV})$, interventricular septum (IVS), left ventricle $(\mathrm{LV})$, and posterior wall $(\mathrm{PW})$, from which wall motion and chamber measurements are derived 
not significantly different at baseline, but differed at each measurement time thereafter (all $P$ s $<0.0005$ ). The same analysis strategy for the dependent variable HR showed that conditions were significantly different at each measurement time $(P<0.01)$. However, the baseline for ESCE was significantly lower than for CPM, and higher at all measurement times thereafter. Analysis of the simple main effects for the dependent variable $\mathrm{VO}_{2}$ demonstrated that baseline conditions were not significantly different. However, at min 15 and 30 of exercise, the ESCE condition was higher $(P s<0.0001)$. This difference was not maintained following exercise. Analysis of the simple main effects for the dependent variable a- $\mathrm{vO}_{2 \mathrm{DIFF}}$ indicated that baseline as well as 15 and $30 \mathrm{~min}$ measurements differed significantly (all $P$ s $<0.01$ ), but not following cessation of activity or thereafter. A significant effect of trial (ie measurement time point) alone was observed for MAP $(P<0.005)$, and $\mathrm{BP}_{\mathrm{SY}}(P<0.0001)$. No effects for condition, trial, or condition by trial interaction were found for $\mathrm{SV}$ or $\mathrm{BP}_{\text {DIAS }}$.

Descriptive statistics for the cardiodynamic and metabolic responses to ESCE and CPM are shown in Tables 3 and 4. When undergoing ESCE, subjects achieved a steady-state $\mathrm{VO}_{2}$ of $712 \pm 300 \mathrm{ml} \mathrm{min}^{-1}$ at min 30 compared to resting oxygen consumption of $284 \pm 100 \mathrm{ml} \mathrm{min}^{-1}$, and a concomitant increase in $\mathrm{a}-\mathrm{vO} \mathrm{O}_{2 \mathrm{DIFF}}$ of $56 \%$. Cardiac output at this exercise intensity increased from $3.5 \pm 1.51 \mathrm{~min}^{-1}$ to $6.0 \pm$ $2.1 \mathrm{~min}^{-1}$, with an average elevation in $\mathrm{HR}$ of $57 \%$. Thus, both $\mathrm{CO}$ and $\mathrm{a}-\mathrm{vO}_{2 \mathrm{DIFF}}$ accounted for the elevated $\mathrm{VO}_{2}$ during $\mathrm{ESCE}$, although the increased $\mathrm{CO}$ was not attributable to elevation in SV.

\section{Discussion}

Chronic adaptation of the cardiorespiratory system to exercise training results from the accumulated effects of intermittent bouts of physical activity during which $\mathrm{CO}$ and a- $\mathrm{vO}_{2 \text { DIFF }}$ are transitionally elevated. While exercise training in persons without disability promotes no net change in resting $\mathrm{CO}$, its $\mathrm{HR}$ and $\mathrm{SV}$ components are desirably lowered and increased, respectively. The explanations for this larger SV include: (1) a larger LV chamber size, (2) increased myocardial contractility, and (3) a longer interval for diastolic filling afforded by the lower heart rate. ${ }^{17,18}$ With respect to the first of these mechanisms, the small LV ventricular chamber size and thin cardiac walls reported in tetraplegic people are also increased in size and thickness following ESCE exercise training, suggesting that both volume and pressure overload accompany acute bouts of this exercise. ${ }^{19}$

The cardiodynamic and metabolic responses to ESCE, both with and without simultaneous upper extremity exercise, have been reported, ${ }^{11-14,20-23}$ and are the subject of recent review. ${ }^{24}$ Studies examining the responses of tetraplegics to ESCE during short- and long-term steady-state exercise have documented (1) elevated $\mathrm{CO}, \mathrm{HR}, \mathrm{SV}$, using transthoracic impedance cardiography (ZCG), (2) heightened $\mathrm{VO}_{2}$ and
Table 2 Summary of ANOVA statistics

\begin{tabular}{lrc}
\hline & $F$ & $P$ \\
\hline Cardiac output (CO) & & \\
Condition & 7.85 & 0.0379 \\
Trial & 5.80 & 0.0082 \\
Condition by trial & 16.48 & 0.0001 \\
Condition at baseline & 0.11 & 0.7379 \\
Condition at minute 15 & 94.98 & 0.0001 \\
Condition at minute 30 & 120.21 & 0.0001 \\
Condition at 5 minutes post & 42.21 & 0.0001 \\
Condition at 15 minutes post & 36.28 & 0.0001 \\
Condition at 30 minutes post & 17.04 & 0.0004 \\
& & \\
Heart rate (HR) & & \\
Condition & 16.88 & 0.0093 \\
Trial & 5.20 & 0.0311 \\
Condition by trial & 20.47 & 0.0001 \\
Condition at baseline & 8.57 & 0.0072 \\
Condition at minute 15 & 58.98 & 0.0001 \\
Condition at minute 30 & 107.19 & 0.0001 \\
Condition at 5 minutes post & 30.43 & 0.0001 \\
Condition at 15 minutes post & 16.59 & 0.0004 \\
Condition at 30 minutes post & 10.13 & 0.0039 \\
Oxygen consumption (VO ${ }_{2}$ ) & & \\
Condition & & \\
Trial & 46.65 & 0.0010 \\
Condition by trial & 5.55 & 0.0444 \\
Condition at baseline & 13.68 & 0.0033 \\
Condition at minute 15 & 0.43 & 0.5171 \\
Condition at minute 30 & 52.83 & 0.0001 \\
Condition at 5 minutes post & 67.66 & 0.01 \\
Condition at 15 minutes post & 2.85 & 0.1039 \\
Condition at 30 minutes post & 0.03 & 0.8616 \\
& 0.05 & 0.8230
\end{tabular}

Arteriovenous oxygen difference (a-v $\left.O_{2 D I F F}\right)$ Condition

Trial

Condition by trial

Condition at baseline

Condition at minute 15

Condition at minute 30

Condition at 5 minutes post

Condition at 15 minutes post

Condition at 30 minutes post

5.55

0.0010

$13.68-0.0033$

$\begin{array}{ll}8.39 & 0.0077\end{array}$

$35.58 \quad 0.0001$

$\begin{array}{ll}44.05 & 0.01\end{array}$

$\begin{array}{ll}3.28 & 0.0823\end{array}$

$0.17 \quad 0.6826$

$0.32 \quad 0.5745$

Stroke volume (SV)

Condition

Trial

Condition by trial by condition

$\begin{array}{ll}1.64 & 0.2560\end{array}$

$\begin{array}{ll}1.11 & 0.3721\end{array}$

$\begin{array}{ll}1.05 & 0.3917\end{array}$

Mean arterial pressure (MAP)

Condition

Trial

$0.01 \quad 0.9353$

$\begin{array}{ll}6.63 & 0.0019\end{array}$

Condition by trial interaction

$0.57 \quad 0.6819$

Systolic pressure (BPSYS

Condition

Trial

Condition by trial interaction

$5.40 \quad 0.0678$

$\begin{array}{ll}10.55 & 0.01\end{array}$

$1.14 \quad 0.3662$

Diastolic pressure $\left(B P_{D I A S}\right)$

Condition

$\begin{array}{ll}0.20 & 0.6749\end{array}$

Trial

$3.95 \quad 0.05$

Condition by trial interaction $\begin{array}{ll}1.42 & 0.2528\end{array}$ 
Table 3 Effects of ESCE and CPM on cardiac output $\left(\mathrm{CO}, 1 \mathrm{~min}^{-1}\right)$, stroke volume $\left(\mathrm{SV}, \mathrm{ml} \mathrm{min}^{-1}\right)$, and heart rate $\left(\mathrm{HR}\right.$, beats $\left.\mathrm{min}^{-1}\right)$. (Mean $\left.\pm \mathrm{SD}, n=6\right)$

\begin{tabular}{|c|c|c|c|c|c|c|}
\hline & Rest & 15 & 30 & $\begin{array}{c}5 \text { min } \\
\text { post }\end{array}$ & $\begin{array}{c}15 \mathrm{~min} \\
\text { post }\end{array}$ & $\begin{array}{c}30 \mathrm{~min} \\
\text { post }\end{array}$ \\
\hline \multicolumn{7}{|c|}{$\mathrm{CO} / \mathrm{ESCE}$} \\
\hline Mean & 3.5 & 5.8 & 6.0 & 5.1 & 4.9 & 4.4 \\
\hline SD & 1.5 & 2.1 & 2.1 & 1.8 & 1.9 & 1.6 \\
\hline \multicolumn{7}{|l|}{$\mathrm{CO} / \mathrm{CPM}$} \\
\hline Mean & 3.6 & 3.4 & 3.3 & 3.5 & 3.4 & 3.4 \\
\hline SD & 1.4 & 1.3 & 1.0 & 0.9 & 0.8 & 0.8 \\
\hline \multicolumn{7}{|c|}{ SV/ESCE } \\
\hline Mean & 50.2 & 53.9 & 53.2 & 52.9 & 53.8 & 51.0 \\
\hline SD & 14.1 & 15.5 & 14.6 & 14.2 & 15.1 & 13.6 \\
\hline \multicolumn{7}{|l|}{ SV/CPM } \\
\hline Mean & 44.2 & 45.2 & 45.7 & 46.1 & 46.1 & 45.4 \\
\hline SD & 5.9 & 7.8 & 5.5 & 6.6 & 6.0 & 5.2 \\
\hline \multicolumn{7}{|c|}{ HR/ESCE } \\
\hline Mean & 70.2 & 105.8 & 110.2 & 94.3 & 87.8 & 84.5 \\
\hline $\mathrm{SD}$ & 23.7 & 21.5 & 20.6 & 18.2 & 18.8 & 17.1 \\
\hline \multicolumn{7}{|l|}{$\mathrm{HR} / \mathrm{CPM}$} \\
\hline Mean & 81.7 & 75.7 & 69.5 & 72.7 & 71.8 & 72.0 \\
\hline SD & 22.2 & 18.1 & 18.5 & 13.4 & 11.4 & 13.4 \\
\hline
\end{tabular}

Table 4 Effects of ESCE and CPM on oxygen uptake $\left(\mathrm{VO}_{2}, 1 \mathrm{~min}^{-1}\right)$ and arteriovenous oxygen difference $\left(\mathrm{a}-\mathrm{vO} \mathrm{O}_{2 \mathrm{DIFF}}\right.$, $\left.\mathrm{ml} 100 \mathrm{ml}^{-1}\right)$. (Mean $\left.\pm \mathrm{SD}, n=6\right)$

\begin{tabular}{|c|c|c|c|c|c|c|}
\hline & Rest & 15 & 30 & $\begin{array}{c}5 \text { min } \\
\text { post }\end{array}$ & $\begin{array}{c}15 \mathrm{~min} \\
\text { post }\end{array}$ & $\begin{array}{c}30 \mathrm{~min} \\
\text { post }\end{array}$ \\
\hline \multicolumn{7}{|c|}{$\mathrm{VO}_{2} / \mathrm{ESCE}$} \\
\hline Mean & 0.281 & 0.681 & 0.712 & 0.353 & 0.252 & 0.237 \\
\hline $\mathrm{SD}$ & 0.10 & 0.33 & 0.30 & 0.06 & 0.05 & 0.05 \\
\hline \multicolumn{7}{|c|}{$\mathrm{VO}_{2} / \mathrm{CPM}$} \\
\hline Mean & 0.239 & 0.220 & 0.230 & 0.246 & 0.241 & 0.222 \\
\hline SD & 0.06 & 0.09 & 0.09 & 0.06 & 0.07 & 0.06 \\
\hline \multicolumn{7}{|c|}{$\mathrm{a}-\mathrm{vO} \mathrm{O}_{2 \mathrm{DIFF}} / \mathrm{ESCE}$} \\
\hline Mean & 8.6 & 12.6 & 13.4 & 8.3 & 5.6 & 6.1 \\
\hline SD & 5.1 & 4.1 & 6.2 & 4.8 & 3.2 & 4.3 \\
\hline \multicolumn{7}{|c|}{$\mathrm{a}-\mathrm{vO} \mathrm{O}_{2 \mathrm{DIFF}} / \mathrm{CPM}$} \\
\hline Mean & 7.3 & 6.6 & 7.0 & 6.9 & 7.1 & 6.2 \\
\hline $\mathrm{SD}$ & 2.2 & 3.1 & 3.0 & 1.4 & 1.7 & 1.4 \\
\hline
\end{tabular}

a-vO $\mathrm{v}_{2 \mathrm{DIFF}}$, and (3) increased MAP. ${ }^{13,14}$ The cardiodynamic and metabolic observations of the present study are in partial accord with these findings. Significant increases in $\mathrm{CO}$ and $\mathrm{VO}_{2}$ were observed during ESCE, although the elevated $\mathrm{CO}$ resulted from significantly elevated HR but not SV, a finding that differs from previous reports. The increased $\mathrm{VO}_{2}$ attained during $30 \mathrm{~min}$ steady-state ESCE was explained both by significantly elevated $\mathrm{CO}$ and a-vO $\mathrm{V}_{2 \mathrm{DIFF}}$, the former of which remained elevated above baseline for as long as $30 \mathrm{~min}$ post-exercise, and the latter of which returned to baseline within 5 min following completion of exercise. As was the case during the ESCE exercise period, the increased $\mathrm{CO}$ during the post-exercise period was also the result of sustained elevation of HR but not SV.

In contrast to the changes observed during ESCE, neither cardiac function nor metabolism was altered from baseline during CPM. While MAP was slightly though insignificantly elevated during CPM, it is possible that some mechanical resistance to blood flow was created during the stretch-relaxation cycles of lower extremity muscles during passive cycling motion, especially as these muscle oppose stretch due to their spastic state. The cardiovascular benefit of this pressor response by itself is negligible, and the contribution of passive motion to the cardiovascular and metabolic responses during ESCE may thus be disregarded. 
Table 5 Effects of ESCE and CPM on mean arterial pressure (MAP, $\left.\mathrm{mm} \mathrm{Hg}^{-1}\right)$, systolic pressure $\left(\mathrm{BP}_{\mathrm{SY}}, \mathrm{mm} \mathrm{Hg}^{-1}\right)$ and diastolic pressure $\left(\mathrm{BP}_{\mathrm{DIAS}}, \mathrm{mm} \mathrm{Hg}^{-1}\right)$. (Mean $\left.\pm \mathrm{SD}, n=6\right)$

\begin{tabular}{|c|c|c|c|c|c|c|}
\hline & Rest & 15 & 30 & $\begin{array}{c}5 \text { min } \\
\text { post }\end{array}$ & $\begin{array}{c}15 \text { min } \\
\text { post }\end{array}$ & $\begin{array}{c}30 \mathrm{~min} \\
\text { post }\end{array}$ \\
\hline \multicolumn{7}{|c|}{ MAP/ESCE } \\
\hline Mean & 79.1 & 82.2 & 79.2 & 70.3 & 67.3 & 69.9 \\
\hline $\mathrm{SD}$ & 15.8 & 11.1 & 11.0 & 7.8 & 9.8 & 13.3 \\
\hline \multicolumn{7}{|c|}{ MAP/CPM } \\
\hline Mean & 78.0 & 85.1 & 79.2 & 70.8 & 67.1 & 68.6 \\
\hline SD & 14.1 & 12.6 & 11.3 & 8.8 & 9.9 & 11.7 \\
\hline \multicolumn{7}{|c|}{$\mathrm{BP}_{\mathrm{SYS}} / \mathrm{ESCE}$} \\
\hline Mean & 105.0 & 104.4 & 113.0 & 94.8 & 86.8 & 89.6 \\
\hline $\mathrm{SD}$ & 13.4 & 15.1 & 17.4 & 12.0 & 8.4 & 14.0 \\
\hline \multicolumn{7}{|c|}{$\mathrm{BP}_{\mathrm{SYS}} / \mathrm{CPM}$} \\
\hline Mean & 96.3 & 104.00 & 102.7 & 96.3 & 87.3 & 86.3 \\
\hline $\mathrm{SD}$ & 12.8 & 15.4 & 13.7 & 13.4 & 8.5 & 12.3 \\
\hline \multicolumn{7}{|c|}{$\mathrm{BP}_{\text {DIAS }} / \mathrm{ESCE}$} \\
\hline Mean & 69.3 & 75.2 & 66.7 & 59.7 & 59.8 & 63.2 \\
\hline $\mathrm{SD}$ & 17.2 & 12.9 & 11.4 & 7.4 & 11.5 & 13.2 \\
\hline \multicolumn{7}{|c|}{$\mathrm{BP}_{\text {DIAS }} / \mathrm{CPM}$} \\
\hline Mean & 63.8 & 73.5 & 72.5 & 66.5 & 63.0 & 62.0 \\
\hline SD & 6.9 & 12.3 & 13.6 & 12.6 & 13.0 & 9.4 \\
\hline
\end{tabular}

The observed increase in CO during ESCE without elevated SV is somewhat paradoxical. To the extent that these reponses differ from those previously reported by Hooker and colleagues ${ }^{13,14}$ in which SV was significantly elevated in tetraplegic people during similar exercise, it is noted that subjects in this study had higher levels of cord injury, were neurologically complete to a greater extent, and had lower baseline $\mathrm{CO}$ and SV. It is not known whether their small ventricles were a consequence of limited physical exertion or restricted wheelchair activity associated with their high levels of injury. Nonetheless, independent wheelchair propulsion was limited in the subjects, none had sufficient upper extremity muscle function to be independent in wheelchair transfers, and only one had any triceps muscle function at all-a poor rating on a 1 to 5 manual muscle rating scale. Moreover, the mean minute ventilation of these subjects was almost one third lower than those reported by Hooker and colleagues, ${ }^{14}$ which may have limited their venous return through inefficient function of the abdominothoracic pump.

In the absence of an intact sympathetic autonomic response, acceleration of $\mathrm{HR}$ during ESCE has been attributed to withdrawal of vagal tone following stimulation of stretch receptors in the right atrium..$^{25,26}$ Cardioacceleration can also be provoked independently of any cardiac innervation by the direct influence of stretch on cardiac pacemaker tissues. ${ }^{25}$ The latter mechanism is especially sensitive to increased atrial distention, and has been shown to increase cardiac rate by more than $50 \%$ in denervated isolated heart preparations, even following slight atrial pressor challenge. ${ }^{27}$ As parasympathetic efferent nerve fibers primarily innervate the cardiac atria and not the ventri- cles, withdrawal of vagal tone during ESCE, and increased sinoatrial node firing may promote a positive cardiac chronotropy without necessarily altering its inotropic state. In contrast, the mechanisms by which increased myocardial force is sustained during exercise in persons without disability include reflex excitation of the ventricular myocardium by autonomic efferents, and heightened myocardial irritability from increased circulating epinephrine released from the adrenal medullae. Neither of these mechanisms is operational in persons with complete tetraplegia. To the extent that resting SV may also be increased by altering the relationship between end-diastolic filling and the force of ventricular contraction (Frank-Starling mechanism) neither ventricular pre-load nor afterload was significantly altered by ESCE in these subjects.

The failure of ESCE to increase SV may also be explained by several factors that limit effective venous return in persons with tetraplegia. First, it is known that acute responses to exercise result from the integrated responses of tissue metabolism, autonomic control, and pulmonary ventilation. ${ }^{28}$ The latter provides not only a means by which steady-state partial pressure of $\mathrm{CO}_{2}\left(\mathrm{pCO}_{2}\right)$ and $\mathrm{pH}$ are maintained at constant levels, but also a mechanism for augmenting venous return during exercise via the abdominothoracic pump mechanism. ${ }^{29}$ This mechanism may play an especially important role in promoting venous return in persons who experience sympathetic dysregulation leading to chronically lowered blood pressure and lower extremity venous pooling. It is interesting to note that the single subject in this study who experienced an increased SV during ESCE also sustained the largest increase in ventilatory tidal volume, and that his beat-to-beat septal wall motion appeared to change in a 
cyclical pattern roughly coincident with the rate of respiration. Nonetheless, an increased SV as a consequence of augmented venous return from heightened frequency and/or depth of ventilation during electrically stimulated exercise in tetraplegics is still speculative.

While it is recognized that resting and exercise $\mathrm{CO}$ in tetraplegic subjects are limited by venous return, the possibility has yet to be investigated that this limitation might also result from their atypical cardiac morphology and performance. It is known that the SV and CO of tetraplegics are small when compared to nondisabled control subjects. ${ }^{2,10}$ Moreover, an unusual pattern of resting ventricular wall movement in chronic tetraplegia has previously been described, one in which wall motion in the atrioventricular groove is characterized by downward and outward movement of the posterior wall when inward motion to promote ejection of the ventricular pre-load is the norm in persons without disability. ${ }^{10}$ The extent to which this atypical cardiac motion is caused by LV atrophy alone is not known, and the contribution of either or both venous unloading and myocardial contractility to suboptimal inotropic response during ESCE remains to be fully understood. Nonetheless, M-mode echocardiograms showed that all but one of our subjects had subtle to more apparent septal hypokinesis, and all had hyperkinetic hearts although to a lesser degree in the single subject with the largest ventricle. No evidence of systolic dysfunction was noted either at rest or during ESCE. As the lack of an increase in cardiac contractility in young and middle aged individuals without disability is an early indicator of systolic dysfunction, this cannot be entirely ruled out in the tetraplegic subjects. In general, no limitation in SV could be attributed to wall motion abnormality, although LV diastolic volumes did not increase during activity. Moreover, because tetraplegics have chronically depressed SV, and the current exercise failed to increase LV diastolic dimension, it is plausible that chronically depressed ventricular filling might result in decreased LV compliance, and explain, in part, the failure of inotropic response to ESCE.

It is well accepted that acute elevation of $\mathrm{VO}_{2}$ sustained during exercise by persons without disability is maintained following the completion of work. ${ }^{16}$ The so-called excess post-exercise oxygen consumption (EPOC) was formerly associated with oxidation of muscle lactate in the post-exercise recovery period. More current evidence suggests linkage to replenishment of intramitochondrial CP used in the phosphorylation of ADP and ATP during muscle contraction. ${ }^{30}$ Several lines of evidence suggest that this rephosphorylation, and therefore the EPOC, is a function of catecholamine secretion during exercise. ${ }^{31}$ First, epinephrine release is a limiting factor in the activation of adipocyte hormone sensitive lipase which stimulates the release of non-esterified free fatty acids during endurance exercise. ${ }^{32}$ Fatty acids then play a significant role in both cellular oxidation and the EPOC. Second, as electrically-stimulated exercise relies to a greater extent on carbohydrate than fatty acid energy substrates, ${ }^{13,14}$ it is not surprising that $\mathrm{VO}_{2}$ falls to near baseline within $15 \mathrm{~min}$ of cessation of activity, a response that limits the post-exercise caloric benefit of the activity.

In addition to the rapid return of $\mathrm{VO}_{2}$ to baseline following ESCE, the results of this study also show immediate or near immediate reduction in all cardiodynamic and metabolic indices following exerciseexcept for an elevation in cardiac output which is the result of heart rate elevation only. The finding of significantly elevated a- $\mathrm{vO}_{2 \mathrm{DIFF}}$ during, but not immediately following, exercise suggests that oxygen transport is facilitated solely through passive diffusion created by a larger $\mathrm{O}_{2}$ gradient between capillary and muscle tissue during ESCE. Increased blood supply is likely shunted to areas of working muscles by local autoregulation including transport of lactate from contracting muscles and an associated drop in postcapillary $\mathrm{pH}$, both of which favor increased blood flow. This increased lactate and decreased $\mathrm{pH}$ following ESCE exercise have previously been reported in mixed-capillary blood samples taken by finger puncture, ${ }^{13}$ levels that are conservative estimates of venous lactate at the site of working muscle. That oxygen diffusion is not altered by erythrocyte-specific transport mechanisms is supported by a previous study in which neither the effector of the rightward shift of the oxyhemoglobin curve (erythrocyte 2,3-DPG) nor the partial pressure at which hemoglobin is $50 \% \quad \mathrm{O}_{2}$ saturated $\left[\mathrm{P}_{50}\right]$, are altered by ESCE. ${ }^{33}$ This finding differs from those of several studies conducted in subjects without disability, suggesting that elevation of 2,3-DPG most often accompanies submaximal exercise of long duration during which the demand for skeletal muscle oxygen delivery and utilization is greatest. ${ }^{34}$

The nominal metabolic responses of tetraplegic persons to ESCE, and their rapid post-exercise return to baseline, represents a limitation of both their unique post-morbid physiology and the manner in which their skeletal muscle is activated by electrical current. This nominal rise in $\mathrm{VO}_{2}$ may be attributed to (1) the effects of physical immobilization and nervous system decentralization on biochemical and contraction properties of skeletal muscles, (2) unique activation of skeletal motor units by transcutaneous electrical stimulation, and (3) atypical exercise responses of persons with autonomic nervous system decentralization secondary to cervical spinal cord injury. All three of these conditions explain a great reliance on glycolytic metabolism to fuel muscle contractions in tetraplegic persons undergoing ESCE and may represent a limiting factor in substrate availability for 2,3-DPG synthesis.

It is known that skeletal muscles undergo biochemical and functional changes favoring characteristics of type II (fast) motor units following either physical deconditioning ${ }^{35}$ or nervous system decentralization, both of which are experienced by persons with cervical SCI. Thus, the recruitment of these fibers during exercise favors anaerobic and not oxidative metabolism. This observation is supported by the 
metabolic findings of several studies in which respiratory exchange ratios (RERs) near or above unity were maintained even under steady-state conditions with low imposed workloads, evidence for the anaerobic quality of the exercise. ${ }^{13,33}$ Additionally, activation of skeletal muscle fibers by transcutaneous electrical current is known to differ from recruitment under central command. This difference results from activation of the large diameter peripheral nerve fibers which have low thresholds for electrical stimulation. ${ }^{36}$ As these large diameter axons also innervate large motor units (type II), the recruitment of these fibers also favors glycolytic metabolism. Thus, while low intensity movements under voluntary command preferentially activate type I (slow) motor units which have highest oxidative capacity, the reciprocal response is observed in electricallystimulated muscle. Last, it is known that autonomic dysfunction associated with cervical SCI may alter exercise responses favoring glycolytic metabolism, a response which has been experimentally mimicked in non-disabled persons undergoing exercise following administration of a beta-adrenergic blocking agent. ${ }^{37}$ Interestingly, the response of the subjects under betablockade, including a reduction in steady-state $\mathrm{VO} 2$ and elevation of RER, parallel those observed for tetraplegics undergoing ESCE.

When compared with the known benefits of endurance exercise in persons without disability, research examining the cardiovascular benefits of electrical stimulation cycling is still in its relative infancy. Comparisons between the two exercise forms are nonetheless inevitable, comparisons which point to the failure of tetraplegics to mount an acute cardiocirculatory response to this treatment characterized by robust increases in heart rate and blood pressure. Nonetheless, the accumulated responses sustained by tetraplegic persons undergoing ESCE have been reported to reshape cardiac architecture ${ }^{10}$ and improve cardiac performance. ${ }^{10-14,20-24}$ Thus, while tetraplegic subjects do not experience the intense acute work capacity responses of non-disabled endurance athletes or recreational exercisers, the cardiovascular and metabolic responses relative to their level of fitness are apparently sufficient to promote sustained conditioning effects. Importantly, the modest elevations of metabolic rate and cardiovascular activity reported here and elsewhere ${ }^{11-14,20-24}$ do not disqualify them from experiencing desirable conditioning benefits of exercise.

This study reinforces the prevailing view that ESCE treatment poses no cardiovascular hazard, although it finds a heretofore unreported cardiac wall motion anomaly which may explain possible limitations in cardiac output for reasons other than deficient exercise venous return. It also addresses the possibility that pulmonary ventilation may have greater influence on cardiac function in tetraplegics than previously addressed, an area of research worthy of additional attention. Importantly, the study finds that alterations in metabolism and cardiovascular function observed during ESCE may not be attributed to passive movement of the lower extremities. As a practical matter, these findings quash the claims of vendors for passive motion devices that purport to improve cardiopulmonary function or level of fitness for survivors of tetraplegia.

\section{Conclusions}

We conclude that unloaded steady-state ESCE performed by tetraplegic subjects increases $\mathrm{CO}$, but only by elevating $\mathrm{HR}$. Increased $\mathrm{SV}$ previously reported in tetraplegic persons undergoing ESCE was not observed, perhaps because our subjects had higher and more complete injuries, less upper extremity function, and/or lower minute ventilation during exercise. The transitory elevation of $\mathrm{VO}_{2}$ during ESCE results from increases in both $\mathrm{CO}$ and a-vO $\mathrm{v}_{2 \mathrm{DIFF}}$. No change in $\mathrm{CO}$, $\mathrm{SV}, \mathrm{HR}, \mathrm{VO}_{2}$, or a-vO $\mathrm{v}_{2 \mathrm{DIFF}}$ is stimulated by CPM alone, and the contribution of passive motion to observed physiological responses during ESCE is inconsequential. Absence of an increased SV is likely due to limited venous return, although reduced depth of ventilation may also limit cardiac volume loading. Septal hypokinesis at rest accompanies elevated HR during exercise, although the extent to which decreased $\mathrm{LV}$ compliance contributes to SV response to ESCE is not known. Post-exercise cardiac function and metabolism return to baseline repidly, a function of the limited ability of ESCE to promote substantial metabolic and cardiac elevation from baseline, as well as absence of a sympathetic responses of tetraplegics to exercise challenge. Mechanisms that explain reduced cardiac response to ESCE and testing of exercise strategies that heighten benefits of this treatment require additional study.

\section{References}

1 Kessler KM et al. Cardiovascular findings in quadriplegic and paraplegic patients and in normal subjects. Am J Cardiol 1986; 58: $525-530$.

2 Figoni SF. Cardiovascular and haemodynamic responses to tilting and to standing in tetraplegic patients: A review. Paraplegia 1984; 22: 99-109.

3 Freyschuss U, Knutson E. Cardiovascular control in man with transverse cervical cord lesions. Life Sci 1969; 8: 421-424.

4 Cardiovascular-cardiopulmonary secondary disabilities In: First Colloquium on Preventing Secondary Disabilities among People with SCI. Atlanta: Centers for Disease Control, 1991; pp 47-54.

5 Ragnarsson KT. The physiologic perspective: cardiovascular system. In: Whiteneck GG (ed). Aging with Spinal Cord Injury. Demos Publications: New York, 1992, pp 73-92.

6 Landry F, Bouchard C, Dumesnil J. Cardiac dimension changes with endurance training: indications of a genotype dependency. J Am Med Assoc 1985; 254: 77-80.

7 Maron BJ. Structural features of the athlete heart as defined by echocardiography. J Am Col Cardiol 1986; 7: 190-203.

8 Demaria et al. Alterations in ventricular mass and performance induced by exercise training in man evaluated by echocardiography. Circulation 1978; 57: 237-244.

9 Morganroth J, Maron BJ, Henry WL, Epstein SE. Comparative left ventricular dimensions in trained athletes. Ann Intern Med 1975; 82: 521-524.

10 Nash MS et al. Reversal of adaptive left ventricular atrophy following electrically-stimulated exercise in human tetraplegics. 
Paraplegia 1991; 29: 590-599.

11 Figoni SF, Glaser RM, Hooker SP. Peak physiologic responses of SCI subjects during FNS leg cycle ergometry. In: Presperin (ed). Proceedings of the 12th Annual Conference of the Rehabilitation Engineering Society of North America; 1989. Rehabilitation Engineering Society of North America: Washington (DC), pp 97-98.

12 Figoni SF, Glaser RM, Hooker SP. Physiologic responses of paraplegics and quadriplegic to passive and active leg cycle ergometry. J Am Paraplegia Sco 1990; 13: 33-39.

13 Hooker SP et al. Physiologic responses to prolonged electrically stimulated leg cycle exercise in the spinal cord injured. Arch Phys Med Rehabil 1990; 71: 863-369.

14 Hooker SP, Figoni SF, Rodgers MM. Metabolic and hemodynamic responses to concurrent voluntary arm crank and electrical stimulation leg cycle exercise in quadriplegic. J Rehabil Res Dev 1992; 29(3): 1-11.

15 Bevegard B, Sheperd J. Regulation of circulation during exercise in man. Physiol Rev 1967; 47: 178-213.

16 Gaesser GA, Brooks GA (1984) Metabolic bases of excessive post-exercise oxygen consumption: a review. Med Sci Sports Exerc 1984; 16: 29-43.

17 Scheuer J, Tipton CM (1977) Cardiovascular adaptations to physical training. Ann Rev Physiol 1977; 39: 221-251.

18 Hammond HK, Froelicher VF. The physiologic sequelae of chronic dynamic exercise. Med Clin N Am 1985; 69: 21-39.

19 Cooper G, Tomanek RJ. Load regulation of the structure, composition, and function of the mammalian myocardium. Circ Res 1982; 50: 788-798.

20 Figoni SF, Glaser RM, Rodgers MM. Hemodynamic responses of quadriplegic to arm. ES-leg, and combined arm + ES-leg ergometry. Med Sci Sports Exerc 1989; 21(Suppl. 2): S96.

21 Figoni SF, Hooker SP, Glaser RM. Physiologic responses to arm cranking and electrical stimulation leg cycling, part II: quadriplegic. Med Sci Sports Exerc 1990; 22 (Suppl.): S43.

22 Hooker SP, Figoni SF, Glaser RM (1989) Physiologic responses to simultaneous voluntary arm crank and electrically stimulated leg cycle exercise in quadriplegic. In: Presperin JJ (ed). Proceedings of the Annual Conference of the Rehabilitation Engineering Society of North America; 1989 (ed.). RESNA Press: Washington DC, pp 99-100.

23 Hooker SP et al. Physiologic effects of electrical stimulation leg cycle exercise training in spinal cord injured persons. Arch Phys Med Rehabil 1992; 73: 470-476.

24. Figoni SF. Exercise responses and quadriplegia. Med Sci Sports Exerc 1993; 25: 433-441.

25 Brice AG et al. Effect of cardiac denervation on cardiorespiratory responses to exercise in goats. J Appl Physiol 1991; 70: $1113-1120$

26 Brunner MJ et al. Carotid sinus baroreceptor reflex control of respiration. Circ Res 1982; 51: 624-636.

27 Blinks JR. Positive chronotropic effect of increasing right atrial pressure in the isolated mammalian heart. Am J Physiol 1956; 186: $299-303$.

28 Dempsey JA, Vidruk EH, Mastenbrook SM. Pulmonary control systems in exercise. Fed Proc 1980; 39: 1498-1505.

29 Fremont-Smith $\mathrm{F}$. The role of elongation and contraction of the inferior vena cava, coincident with respiration, in the return of blood to the heart: report of an observation on men. J Mt Sinai Hosp 1942; 9: 432-434.

30 Mahler M, Homsher E. Metabolic rate changes in parallel with creatine level during non-steady states in frog skeletal muscie. Fed Proc 1982; 41: 979.

31 Gladden L, Stainsby W, Maclntosh B. Norepinephrine increases canine skeletal muscle $\mathrm{VO}_{2}$ during recovery. Med Sci Sports Exerc 1982; 14: 471-476.

32 Kjaer M, Secher NH, Bach FW, Galbo H. Role of motor center activity for hormonal changes and substrate mobilization in exercising man. Am J Physiol 1987; 253: R687-R695.

33 Nash MS, Isaacks RE, Hughes JR, Green BA. Acute effects of electrically-stimulated cycling exercise on oxyhemoglobin affinity in quadriplegics. Proc Elec Magn Biol Med 1993; 1: $782-784$.

34 Eaton JW, Faulkner JA, Brewer GJ. Response of the human red cell to muscular activity. Proc Soc Exp Biol Med 1969; 132: 886-887.

35 Sergeant AJ, Davies CTM, Edwards RHT. Functional and structural changes after disuse of human muscle. Clin Sci Mol Med 1977; 52: 337.

36 Spielholz NI (1990) In: Basmajan JV, Wolf SL (eds), Therapeutic Exercise (5th edn). Williams \& Wilkins: Baltimore (MD), pp 68-69.

37 vanBaak MA et al. Beta-blockade and lipolysis during endurance exercise. Med Sci Sports Exerc 1992; 24: S176. 